\title{
JOPE
}

\section{PENGARUH METODE LATIHAN FRONT CONE HOPS TERHADAP POWER OTOT TUNGKAI ATLET REMAJA PUTRA PENCAK SILAT WALET PUTI PEKANBARU}

\author{
SuciMariati $^{1}$, Drs. Ramadi, S.Pd, M.Kes, AIFO ${ }^{2}$, Aref Vai, S.Pd, M.Pd ${ }^{3}$ \\ Email: suciuniversitas@gmail.com,Mr.Ramadi59@gmail.com,aref.vai@lecture.unri.ac.id
}

\section{ABSTRAK}

Tujuan dari penelitian ini dilakukan untuk mengetahui apakah ada pengaruh latihan Front Cone Hops terhadap power otot tungkai atlet remaja putra Pencak Silat Walet Puti Pekanbaru. Jenis penelitian yang digunakan adalah eksperimen dan menggunakan desain penelitian one grup preetest-posttest design. Populasi dalam penelitian ini adalah atlet remaja putra pencak silat Walet Puti Pekanbaru yang berjumlah 10 orang. Adapun teknik sampel yang digunakan adalah total sampling (sampel jenuh), di mana semua populasi dijadikan sampel. Dengan demikian sampel pada penelitian ini berjumlah 10 orang sampel atlet remaja putra Pencak Silat Walet Puti Pekanbaru. Instrumen yang digunaka adalah Tes Loncat Jauh Tanpa Awalan. Setelah itu, data diolah dengan statistik, untuk menguji normalitas dengan uji liliefors pada taraf signifikan $\alpha(0.05)$. Hipotesis yang diajukan adalah adanya pengaruh latihan Front Cone Hops terhadap Power otot tungkai atlet remaja putra pencak silat Walet Puti Pekanbaru. Berdasarkan hasil analisis, terdapat rata-rata pretest 215,5 dan posttest 222,9 ada peningkatan rata-rata nilai beda sebesar 7,4 dengan uji $\mathrm{t}$ bahwa $\mathrm{t}_{\text {hitung }}=8,41>$ dari $\mathrm{t}_{\text {tabel }}=$ 1.83. Berarti $t_{\text {hitung }}>t_{\text {tabel }}$. Dengan demikian teRdapat pengaruh latihan Front Cone Hops terhadap Power otot tungkai atlet remaja putra pencak silat Walet Puti Pekanbaru.

Kata Kunci: Front Cone Hops, Power Otot Tungkai

\section{ABSTRACT}

The purpose of this research was conducted to find out if there is the effect of front cone hops exercise method on limb muscle power on on boy teen athlete pencak silat walet puti pekanbaru. Type of research used is experiment and using one grup preetest-posttest design. Population this research is boy teen athlete pencak silat Walet Puti Pekanbaru is the entire populations of 10 peoples. While the sample technique used is total sampling (saturated sample) where all the population is sampled. The sample in this amounted to 10 peoples of boy teenathlete pencak silat Walet Puti Pekanbaru. The instrument used standing broad jump. After that, the data is processed with statistics, normality test with liliefors test at significance level $\alpha$ (0.05). The hypothesis is The Effect Of Front Cone Hops Exercise Method on the power of limb Muscle on boy teen athlete pencak silat Walet Puti Pekanbaru. Based on the analysis of statistical data, there are an average pre-test 211,5 and an average post-test 222,9, then the data is normal with an increase of 7,4 . Based on t test analysis produces $t_{\text {hitung }}=8,41>t_{\text {tabel }}=1,83$. Meaning $t_{\text {hitung }}>t_{\text {tabel }}$. Thus, there is the effect of front cone hops exercise method on limb muscle power of limb Muscle on boy teen athlete pencak silat Walet Puti Pekanbaru

Keywords: Front Cone Hops, Limb Muscle Power 


\section{PENDAHULUAN}

Menurut Mulyana (1995:62)

olahraga pada dasarnya merupakan sebuah kompetisi, dan seluruh kompetisi tersebut tergantung pada kejujuran (fair play). Kompetisi dipandang sebagai lawan dari kerjasama yang khusus. Didalam kompetisi, ada dua orang kompetitor atau lebih bekerjasama saling member tantangan yang memunkinkan mereka untuk menampilkan performa terbaiknya. Salah satu olahraga kompetitor adalah pencak silat. Suwirman (1999:8-9) mengatakan bahwa pencak silat adalah warisan budaya leluhur dari negeri Indonesia.

Secara umum, komponenkomponen kondisi fisik meliputi daya tahan, stamina, kelentukan, kekuatan, power, kecepatan, koordinasi dan keseimbangan (Harsono, 1988:153226). Sedangkan secara khususnya untuk cabang olahraga pencak silat menurut Joko Subroto (1996:22) pembinaan atau cabang olahraga pencak silat antara lain meliputi unsure-unsur: 1) Latihan daya tahan (endurance); 2) Latihan kekuatan otot (muscle strength); 3) Latihan kecepatan (speed); 4) Latihan tenaga ledak/daya ledak (muscle explosive power); 5) Latihan ketangkasan (agility); 6) Latihan kelenturan (flexibility); 7) Latihan keseimbangan (balance).

Berdasarkan observasi di lapangan pada saat laga, peneliti menemukan masalah pada power otot tungkai yang terlihat ketika atlet-etlet remaja tersebut mengaplikasikan salah satu teknik yaitu tendangan. Tendangan ini dilakukan kurang sempurna koordinasinya, tidak mempunyai power sehingga tendangan tersebut mudah terbaca oleh lawan, mudah ditangkis, dielak dan ditangkap. Tidak adanya power otot tungkai menyebabkan juga kerugian pada mereka saat bertanding karena juri sering tidak mencatat nilai tendangan mereka dikarenakan tendangn mereka kurang bertenaga dan mantap.

Penulis menduga kurangnya latihan yang mengarah pada peningkatan power, dalam hal ini adalah power otot tungkai. Kurangnya power otot tungkai mereka terlihat pada hasil loncat jauh tanpa awalan yang penulis berikan. Dimana dapat penulis simpulkan hasil loncat jauh tanpa awalan para atlet remaja tersebut yaitu 8 orang dalam kategori "kurang", 1 orang dalam kategori "sangat kurang", dan hanya 1 orang dalam kategori "sedang".

Oleh karena itu penulis memberikan latihan pada atlet remaja putra Pencak Silat Walet Puti Pekanbaru yang mengacu pada peningkatan power otot tungkai melalui metode plyometric, dan salah satu bentuk metode plyometric yaitu front cone hops. Alasan penulis memilih bentuk latihan front cone hops karena dalam bentuk latihan front cone hops merupakan dasar untuk mengembangkan kekuatan yang terdapat pada tungkai dan pinggul, latihan ini dilakukan dalam suatu rangkaian loncatan explosive yang cepat. Setiap cabang olahraga menuntut untuk membutuhkan power yaitu kombinasi atau perpaduan antara kecepatan maksimal dan kekuatan, tidak terkecuali cabang olahraga pencak silat.

Menurut Harsono (2017:39), tujuan utama latihan olahraga prestasi adalah untuk membantu atlet untuk meningkatkan keterampilan dan prestasinya semaksimal mungkin. Untuk mencapai tujuan tersebut ada empat aspek latihan yang perlu dilatih secara seksama, yaitu :

1. Latihan Fisik

Perkembangan kondisi fisik yang menyeluruh amatlah penting, oleh karena tanpa kondisi fifik yang baik atlet tidak akan dapat mengikuti latihan-latihan dengan sempurna. Tujuan utamanya ialah untuk meningkatkan potensi faallah dan mengebangkan kemampuan biomotorik ketingkat yang setinggi tingginya agar prestasi yang paling tinggi juga bisa dicapai.

2. Latihan Teknik

Latihan teknik adalah untuk mempermahir teknik-teknik gerakan yang diperlukan agar atlet terampil melakukan cabang olahraga yang digelutinya. Kesempurnaan teknik teknik dari setiap gerakan adalah penting oleh karena akan menentukan gerak keterampilan secara keseluruhan.

3. Latihan Taktik

Bertujuan mengembangkan dan menumbuhkan 
daya tafsir pada atlet katika melaksanakan kegiatan olahraga yang bersangkutan. Yang dilatih yaitu bentuk pola-pola permainan, strategi pertahanan atau penyerangan, sehingga dapat berkembang menjadi suatu kesatuan gerak yang sempurna.

4. Latihan Mental

Latihan ini juga sangat penting dengan ketiga aspek tersebut diatas, karena betap sempurna pun kondisi fisik, teknik, serta taktik. Apabila mentalnya tidak turut berkembang, maka prestasi tinggi sulit dan tidak mungkin akan dicapai. Latihan ini untuk meningkat. Kedewasaan serta emosional atlet seperti semangat dalam bertanding, sikap pantang menyerah, serta bisa mengatur emosi pada saat berada dalam situasi stress, fair play, percaya diri, kejujuran, kerja sama serta sifat-sifat positif lainnya.

\section{METODELOGI PENELITIAN}

Adapun jenis penelitian ini adalah eksperimen lemah dimana hanya menggunakan satu kelompok eksperimen. Desain dalam penelitian ini adalah one-group pretest-posttest design dimana menurut Sugiyono (2014:74) menjelaskan bahwa pada desain ini terdapat pretest, sebelum diberi perlakuan. Dengan demikian hasil perlakuan dapat diketahui lebih akurat, karena dapat membandingkan dengan keadaan sebelum diberi perlakuan.

Menurut Arikunto (2006:131), populasi adalah keseluruhan dari subjek penelitian. Populasi dalam penelitian ini adalah atlet remaja putra Pencak Silat Walet Puti Pekanbaru yang berjumlah 10 orang. Menurut Arikunto (2006:131), sampel adalah sebagian atau wakil populasi yang diteliti. Berhubung jumlah sampel hanya 10 orang maka peneliti mengambil seluruh dampel dalam penelitian ini. Pengambilan sampel dijadikan dengan mengambil seluruh populasi dijasikan sampel (total sampling). Teknik pengambilan sampel dengan cara sampling jenuh yaitu teknik pengambilan sampel bila semua anggota populasi digunakan sebagai sampel (Sugiyono, 2014:85).

\section{HASIL PENELITIAN DAN PEMBAHASAN}

Data yang diambil melalui tes dan pengukuran terhadap 10 orang atlet remaja putra Pencak Silat Walet Puti Pekanbaru. Variabel-variabel yang ada pada penelitian ini yaitu metode latihan front cone hops yang dilambangkan dengan $\mathrm{X}$ sebagai variabel bebas, sedangkan hasil power otot tungkai dilambangkan dengan $\mathrm{Y}$ sebagai variabel terikat.

Setelah dilaksanakan penelitian yang diawali dari pengambilan data awal (Pre-test) dilakukan perhitungan yang menghasilkan $L_{\text {hitung }}$ sebesar $\mathrm{L}_{\text {hitung }}$ sebesar $\mathbf{0 , 1 1 2 3}$ dan $\mathrm{L}_{\text {tabel }} \mathbf{0 , 2 5 8}$ dapat disimpulkan data hasil pre-test berdistribusi normal dan dari pengambilan data akhir (Post-test) dilakukan perhitungan yang menghasilkan $L_{\text {hitung }}$ sebesar $\mathbf{0 , 1 5 1 7}$ dan $\mathrm{L}_{\text {tabel }}$ sebesar $\mathbf{0 , 2 5 8}$ dapat disimpulkan data hasil post-test berdistribusi normal. Kemudian berdasarkan analisis uji $\mathrm{t}$ diperoleh hasil $t_{\text {hitung }}$ sebesar $\mathbf{8 , 4 1}$ dan $t_{\text {tabel }}$ sebesar 1,83. Berarti $t_{\text {hitung }}>t_{\text {tabel, }}$ maka $\mathrm{H}_{0}$ ditolak dan $\mathrm{H}_{1}$ diterima.

Dari hasil pengujian hipotesis yang menunjukan terdapat pengaruh pada metode latihan front cone hops terhadap power otot tungkai yang dbutuhkan untuk mendukung teknik atlet pada saat melakukan latihan maupun saat mengikuti pertandingan pencak silat. Dengan demikian berhasil tidaknya tujuan yang akan dicapai akan dipengaruhi oleh penerapan prinsip-prinsip latihan yang diperlukan dalam membuat program latihan. Salah satu jenis latihannya yaitu Front Cone Hops.

Setelah di lakukan pretest dan posttest terdapatlah hasil yang berbeda-beda setiap teste, hal itu disebabkan oleh kegigihan dan faktor lainnya dalam berlatih. Mereka ada yang rajin dan ada pula yang jarang datang latihan dan kurang minat mengikuti latihan yang diberikan oleh pelatih. Jadwal latihan yang terganggu juga mempengaruhi hasil tes ini, ada beberapa jadwal latihan yang di batalkan di sebabkan oleh cuaca yang 
tidak mendukung atau hujan serta jadwal-jadwal try out mereka. Seperti Hendra yaitu sampel yang mendapatkan nilai tertinggi dari 9 orang sampel lainnya, dikarenakan ketika pada saat jadwal latihan ia selalu fokus, serius, semangat dan selalu datang ketika latihan. Sampel yang memperoleh nilai terendah adalah Riski, dikarenakan jarang datang pada saat latihan dan tidak serius kare ia juga memang bermasalah dengan kesehatan dan fisik, ia sering sakit dan postur tubuhnya juga yang paling pendek diantara sampel-sampel lainnya. Sedangkan sampel yang memperoleh nilai beda tertinggi adalah Hendra, dikarenakan nilai pretest dan posttestnya ia mendapatkan nilai yang tertinggi juga serta antara nilai pretest dan posttest terdapat perubahan nilai yang cukup signifikan maka hal itu sangat berpengaruh pada nilai bedanya sehingga Hendra memperoleh nilai beda tertinggi yaitu 13. Sementara itu yang memperoleh nilai beda terendah adalah Sadam dikarenakan ia terlalu sering tidak mengikuti latihan dan kalaupun latihan dia pasti tidak serius melaksanakan instruksi yang peneliti berikan, juga gerakan yang dilakukannya selalu tidak benar sehingga mendapat nilai beda terendah yaitu 5. Satu lagi sampel yang juga memperoleh nilai beda terendah yaitu Fadly, ia memperoleh nilai 5 juga dikarenakan dia akan bertanding dan dituntut harus bisa menjaga berat badannya agar tidak over karena ia akan bertanding dalam waktu dekat jadi latihan untuk Fadly tidak terlalu diforsir.

\section{Pre test}

Setelah dilakukan tes loncat jauh tanpa awalan sebelum dilaksanakan metode latihan front cone hops maka didapat data awal (pre-test) tes loncat jauh tanpa awalan adalah sebagai berikut : skor tertinggi 222, skor terendah 209 dengan rata-rata 215,5 , standar deviasi 4,48, dan varians 20,07.

\section{Post test}

Setelah dilakukan tes loncat jauh tanpa awalan sebelum dilaksanakan metode latihan front cone hops maka didapat data akhir (post-test) tes loncat jauh tanpa awalan adalah sebagai berikut : skor tertinggi 235, skor terendah 215, dengan rata-rata 222,9, standar deviasi 6,85, dan varians 46,92 .

Tabel 1 Hasil Uji Normalitas Pretest dan Post-test

Loncat Jauh Tanpa Awalan

\begin{tabular}{|l|c|c|l|}
\hline $\begin{array}{l}\text { Variabe } \\
\text { l }\end{array}$ & $\mathbf{L}_{\text {hitung }}$ & $\mathbf{L}_{\text {tabel }}$ & $\begin{array}{l}\text { Keteranga } \\
\mathbf{n}\end{array}$ \\
\hline $\begin{array}{l}\text { Hasil } \\
\text { Pre-test }\end{array}$ & 0,112 & 0,25 & Normal \\
Soccer & 3 & 8 & \\
Loncat & & & \\
Jauh & & & \\
Tanpa & & & \\
Awalan & & & \\
\hline $\begin{array}{l}\text { Hasil } \\
\text { Post-test }\end{array}$ & 0,151 & 0,25 & Normal \\
Loncat & 7 & 8 & \\
Jauh & & & \\
Tanpa & & & \\
Awalan & & & \\
\hline
\end{tabular}

Sumber: Data olahan peneliti.

Dari tabel di atas terlihat bahwa data hasil pre-test Loncat Jauh Tanpa Awalan setelah dilakukan perhitungan menghasilkan $\mathrm{L}_{\text {hitung }}$ sebesar $\mathbf{0 , 1 1 2 3}$ dan $\mathrm{L}_{\text {tabel }} \mathbf{0 , 2 5 8}$. Dapat disimpulkan penyebaran data hasil pre-test Loncat Jauh Tanpa Awalan adalah berdistribusi normal. Untuk pengujian data hasil post-test Loncat Jauh Tanpa Awalan menghasilkan $\mathrm{L}_{\text {hitung }}$ sebesar 0,1517 dan $\mathrm{L}_{\text {tabel }}$ sebesar 0,258. Dapat disimpulkan penyebaran data hasil post-test Loncat Jauh Tanpa Awalan adalah data berdistribusi normal.

\section{SIMPULAN DAN REKOMENDASI Simpulan}

Berdasarkan permasalahan yang terdapat pada atlet pencak silat Walet Puti Pekanbaru, peneliti berupaya meningkatkan power pada otot tungkai mereka dengan memberikan metode latihan Front Cone Hops. Jenis dalam penelitian ini adalah eksperimen lemah dimana hanya menggunakan satu kelompok 
eksperimen. Desain dalam penelitian ini adalah one-group pretest-posttest design dimana menurut Sugiyono (2014:74) menjelaskan bahwa pada desain ini terdapat pretest, sebelum diberi perlakuan. Dengan demikian hasil perlakuan dapat diketahui lebih akurat, karena dapat membandingkan dengan keadaan sebelum diberi perlakuan.

Sebelum dilakukan analisis, terlebih dahulu dilakukan pree-test dengan hasil rata-rata sebesar 215,5 kemudian dilakukan metode latihan Front Cone Hops selama 16 kali pertemuan pada atlet remaja putra Walet Puti Pekanbaru sebanyak 10 orang dan didapatkan hasil rata-rata post-test sebesar 222,9. Berdasarkan statistik analisis uji-t maka didapatkan nilai beda sebesar 2,79 dan menghasilkan thitung sebesar 8,41 dan ttabel sebesar 1,83. Berarti titung> ttabel. Dapat disimpulkan bahwa metode latihan Front Cone Hops (X) memberikan Pengaruh Terhadap Power Otot Tungkai (Y) Atlet Remaja Putra Pencak Silat Walet Puti Pekanbaru.

\section{Rekomendasi}

Saran yang mungkin dapat berguna dalam upaya meningkatkan metode latihan front cone hops pada atlet pencak silat adalah:

1. Bagi peneliti, sebagai masukan penelitian lanjutan dalam rangka pengembangan ilmu dalam Pendidikan Olahraga.

2. Bagi pelatih, agar dapat menerapkan metode latihan Front Cone Hops untuk meningkatkan power otot tungkai.

3. Bagi atlet silat, agar bisa lebih giat dalam berlatih terutama dalam meningkatkan teknik-teknik pencak silat.

4. Bagi pembaca, penelitian ini bermanfaat sebagai bahan masukan dalam menyusun strategi latihan dalam olahraga yang mampu meningkatkan penguasaan teknik olahraga dikalangan atlet pada umumnya dan atlet pencak silat pada khususnya.

\section{DAFTAR PUSTAKA}

Anggaran Dasar Rumah Tangga Perguruan Silat Walet Puti Tahun 1970, Kisaran-Medan.

Arikunto, Suharsimi. 2006. Prosedur Penelitian Suatu Pendekatan Praktik(Edisi Revisi VI). Jakarta: PT. Rineka Cipta.

A. Chu, Donald. (1992). Jumping Into Plyometrics.California.

Printer: United Graphics.

Harsono. (1988). Coaching dan Aspek-aspek Psikologi Dalam Coaching. Jakarta: CV. Tambak Kusuma.

Irawadi, Hendri. 2014. Kondisi Fisik dan Pengukurannya. UNP PRESS: Sukabina.

Kosashi, Engkos. 1992. Olahraga Teknik dan Program Latihan. Jakarta: Akademika Presindo

Lesmana, Ferry. 2012. Panduan Pencak Silat (Kategori Pencak Silat Tanding). Yogyakarta: Nusa Media.

Lubis, Johansyah. (2014). Pencak Silat Edisi Kedua. Jakarta: PT. Raja Grafindo Persada.

Lumintuarso, Ria. (2013). Teori Kepelatihan Olahraga. Jakarta: Lembaga Akreditasi Nasional Keolahragaan. Jakarta: LANKOR.

Mulyana.2013. Pendidikan Pencak Silat Membangun Jati Diri dan Karakter Bangsa. Bandung. PT. Remaja Rosdakarya.

Ritonga, Zulfan. 2007. Statistik Untuk Ilmu-Ilmu Sosial. Cendekia Insani: Pekanbaru.

Sajoto. 1988. Peningkatan \& Pembinaan Kekuatan Kondisi Fisik Dalam Olahraga. Semarang. Dahara Prize.

Subroto, Joko. 1996. Pembinaan Pencak Silat Fisik, Teknik, Taktik dan Mental. Solo: CV. Aneka.

Sugiyono. 2014. Metode Penelitian Kuantitatif, Kualitatif, dan R\&D. Bandung: Alfabeta.

Suwirman. 1999. Pencak Silat Dasar. DIP Proyek Universitas Negeri Padang.

Undang-Undang Republik Indonesia Nomor 3 Tahun 2005 Tentang Sistem Keolahragaan Nasional, Jakarta. 